\title{
International Food Safety Standards: Catalysts for Increased Chinese Food Quality?
}

WENCONG LU AND SØREN KJELDSEN-KRAGH

\begin{abstract}
Increasingly, during the last 10-15 year, the question about food safety has been a topic of great concern both nationally and internationally. Traditionally, there has been a conflict of interest between the developed countries with higher food safety standards and the developing countries with lower food safety rules. As long as adequate international rules exist, perhaps the view of these rules as barriers to trade should be replaced by the view of standards as catalysts for increased food quality. This article looks at the food safety issue in China, the largest developing country. The Chinese exports of food products have been confronted with trade restrictions because the products did not comply with the high food standards in the USA, the EU and Japan. These difficulties have contributed to a greater concern in China about the quality of the food products. In the last ten years, a series of changes in the rules and in the administration of food standards have taken place. This is a complicated task because it affects the whole food industry. The article tries to cast light on these important questions. What have been the consequences of inadequate food safety regulations in China? What has been done up to now to improve the food quality standards in China? What further initiatives should be taken to improve the situation in the future?
\end{abstract}

Keywords: Food safety, import restriction, productstandards, food quality, competitiveness.

\section{Introduction}

Along with increasing public awareness of health and environment, food safety issues have risen in importance. The problem related to food safety standards have been on the agenda in the global trade system for several years. Food safety standards in developed countries have become more stringent and have increased. These standards are the source of concern among many developing countries (OECD, 2004; World Bank, 2005). Therefore the role of food safety standards in international trade has become an important topic for discussion in recent literature. The view of the 'standards-as-barriers' to trade holds that increased food safety standards in developed countries are used as protectionist tools or in a discriminatory manner (Roberts, et al., 1999; Caswell, 2003). Conversely, 
the 'standards-as-catalysts' is more optimistic view that emphasizes the opportunities provided by emerging food quality requirements and the possibility that developing countries could use them to increase their competitive advantages (Jaffee and Henson, 2005).

High food safety standards might be considered as trade barriers by developing countries. However, if the safety standards are complying with the Sanitary Phytosanitary Agreement in the WTO and the Codex Alimentarius Commission, based on verdicts by expert committees under the FAO and $\mathrm{WHO}$, the safety standards are legitimate. Developing countries cannot use the dispute settlement body in the WTO. If the developing countries do not accept the present rules, they either have to open bilateral negotiations with the developed countries to try to convince the country to apply less stringent standards, or to try through multilateral negotiations to change the present set of WTO rules.

Chinese food trade has increased markedly in recent years in spite of a series of cases where the Chinese products did not comply with the safety regulations in the importing countries. This article is not dealing with the question of whether food safety standards are either open or disguised trade barriers but is looking at the food safety standards in the developed countries as catalysts for improving the quality of Chinese food products.

This article analyses how Chinese food products have been subject to restricted import conditions when China has been trying to access the markets in the USA, the EU and Japan. China has realized those problems, and the article shows how China has already introduced a series of changes with the purpose of achieving an improved product standard, which makes it easier for China to avoid restricted exports to the main export markets. However, what has been done is not sufficient, and further steps have to be undertaken to improve the quality of Chinese food products.

\section{Chinese food trade}

China is the largest food producing and food consuming country in the world. China is also playing an increasing role in global food trade. Since the implementation of reform policies initiated in 1978, and especially since the accession to the WTO in 2001, Chinese exports in both raw and processed food products, has increased from US\$ 3 billion in 1980 to US\$ 31 billion in 2006 (see Table 1). 
TABLE 1: Development of Chinese food exports and imports, US\$ billion

\begin{tabular}{|l|c|c|c|}
\hline & 1980 & 2001 & 2006 \\
\cline { 2 - 4 } Total exports of food products & 2.99 & 15,98 & 31,03 \\
\hline Total imports of food products & 2.93 & 11,78 & 31,99 \\
\hline Food exports to US & 0.11 & 1,22 & 3,78 \\
to EU & 0.26 & 1,71 & 4,34 \\
to Japan & 0.47 & 5,72 & 8,21 \\
\hline Food imports from US & 1.33 & 2,29 & 7,59 \\
from EU & 0.03 & 0,64 & 1,67 \\
from Japan & 0.01 & 0,23 & 0,41 \\
\hline Food product exports as a share of total exports & 16,47 & 6,00 & 3,20 \\
\hline Food product imports as a share of total imports & 14,62 & 4,84 & 4,04 \\
\hline
\end{tabular}

Source: Chinese Statistics Year Book 2006 and UNCOMTRADE Database

The significant increase in international trade has been an important force in the rapid growth of the Chinese economy in the past two decades. This trend has been strengthened following China's accession to the WTO in 2001. As global food trade has been gradually liberalized, China has become an important food trader in the world. Table 1 shows the development of the Chinese food trade since the 1980s.

As seen in Table 1, the share of food exports in total exports decreased from 16.5 percent in 1980 to 3.2 percent in 2006. Despite its rapidly declining share in total trade value, China's food exports have grown significantly from 1980 to 2006, that is, ten times. The trade balance in food products was in equilibrium in 1980, and then gradually an export surplus developed up until 2001, when China entered the WTO. Since then, food imports have increased more than the food exports. Around half of the Chinese food exports went to the USA, the EU and Japan.

Table 2 shows the commodity composition of Chinese food exports and imports. Ten years ago, around half of the exports consisted of seafood and fish, vegetables, and fruits. This share was the same in 2001, but since then, the exports of seafood, vegetables and fruits have expanded more than the average exports. In 1996 the exports of animal products were relatively important, but since then the exports have stagnated in value. In imports, the dominant item in recent years has been edible oil and oilseeds, which in 2005 amounted to 40 percent of the total food imports. 
TABLE 2: The Commodity composition of Chinese food exports and imports, US\$ billion

\begin{tabular}{|l|ccc|ccc|}
\hline & \multicolumn{3}{|c|}{ Exports } & \multicolumn{3}{c|}{ Imports } \\
\cline { 2 - 7 } Animal products & 1996 & 2001 & 2005 & 1996 & 2001 & 2005 \\
\cline { 2 - 7 } Vegetables and fruits & 2,44 & 2,03 & 2,35 & 0,35 & 1,03 & 1,38 \\
Cereal & 3,05 & 3,68 & 7,21 & 0,29 & 0,66 & 1,34 \\
Edible oil and oilseeds & 0,64 & 1,55 & 2,37 & 2,64 & 0,78 & 1,82 \\
Aquatic products & 1,44 & 1,03 & 1,67 & 2,11 & 4,12 & 11,47 \\
Coffee, cocoa and tea & 3,21 & 4,64 & 8,71 & 0,61 & 1,35 & 2,91 \\
Sugar & 0,54 & 0,57 & 1,04 & 0,09 & 0,1 & 0,22 \\
Beverages and alcohol & 0,31 & 0,16 & 0,42 & 0,43 & 0,38 & 0,45 \\
Feed & 0,47 & 0,57 & 0,72 & 0,04 & 0,15 & 0,41 \\
Others & 0,35 & 0,29 & 0,48 & 1,3 & 0,64 & 1,31 \\
Total & 1,36 & 1,46 & 2,21 & 0,61 & 2,58 & 7,35 \\
\hline
\end{tabular}

Source: Chinese Statistics Year Book 2006 and UNCOMTRADE Database

In spite of the food safety problems discussed in the next section, it can be concluded that Chinese food exports have expanded significantly. The commodity composition of Chinese food exports shown in Table 2, seem to reveal that China has comparative advantages in the production of seafood, vegetables, fruits and tea. The exports of these products have increased more than the average, in spite of the fact that some of the most important food safety cases are related to these products.

\section{Restricted imports on Chinese food products due to food safety regulations}

As its participation in world food trade has increased, China has increasingly been confronted with challenges related to food safety, especially for some higher-valued food products including fruits, vegetables, fish and poultry, which are the important products in Chinese exports and cover about two third of the total food exports in 2005 (see Table 2). China has not always been able to conform to the standards which have hindered the expansion of Chinese exports. There are several cases in which Chinese food exports in recent years have been affected by sanitary and phytosanitary measures, which were implemented by governments to protect human, animal and plant life and health. 
In recent years, health-related requirements on food exports from China are becoming more stringent and complex in its main export markets. For example, EU legislation requires exporters of fishery products to label consignments identifying the species name, production method and catch area. Additionally, Japanese standards for levels of pesticide residues in food products, especially fruits, vegetables, tea, cereals, animal and aquatic products, have become increasingly rigorous by the enforcement of the so-called 'Positive List System' since May 2006.

In the following discussion, we show some important cases of the food trade issue between China and its main partners since 1997. They illustrate market access barriers on Chinese food exports. According to the estimates of the Chinese government, the loss of Chinese food trade due to these concerns accounted for US\$ 9 billion in 2002, and about 90 percent of Chinese food trade firms are affected by the trade loss (China Daily 2003), revealing a gap between Chinese and international food safety standards.

All the cases mentioned in the following are important because the commodity range covers two third of the total Chinese food exports. In recent years, these cases have been discussed widely in Chinese professional journals and press.

\section{The United States}

The US is one of China's main trade partners for food products. In 2006, the total value of food export amounted to US $\$ 3.78$ billion. The export of Chinese fishery products amounted to US\$ 1.3 billion, representing 90 percent of the total of American imports of fishery products. Exports of Chinese fruits, processed fruit products and fresh squeezed concentrate to the US accounted for nearly US\$ 0.57 billion in 2006 . The US has enforced strict sanitary and phytosanitary standards for food imports from China in the last years.

Table 3 illustrates some cases of the market access restrictions on Chinese food exports to the US. For example, Chinese frozen shrimps and honey exported to the US in 1997 and 2002 were restricted because of high trace levels of residues of animal waste and chloramphenicol. These measures have led to losses for Chinese producers, in a sector where China is one of the largest producers of honey in the world and with an annual production of over 200 thousand tons or approximately one-quarter of total world production. These safety barriers of Chinese food to the US market have also contributed to an adverse balance of bilateral food trade. In 2006, the deficit of Chinese food trade with the 
USA reached $\$ 3.8$ billion. This has exhibited a continuously increasing trend since 2001, when China joined the WTO.

TABLE 3: Restricted imports of Chinese food products in the USA

\begin{tabular}{|c|l|l|l|}
\hline Year & \multicolumn{1}{|c|}{ Product } & \multicolumn{1}{|c|}{ Main problem } & \multicolumn{1}{|c|}{ Trade impacts } \\
\hline 1997 & Frozen shrimps & $\begin{array}{l}\text { Excessive chloramphenicol } \\
\text { residues }\end{array}$ & Import restricted \\
\hline 1998 & $\begin{array}{l}\text { Canned mush- } \\
\text { rooms }\end{array}$ & Unqualified processes & Tariff increase of 154-198\% \\
\hline 2002 & Honey & $\begin{array}{l}\text { Excessive chloramphenicol } \\
\text { residues }\end{array}$ & Maximal export to 500 Tons \\
\hline 2002 & Shrimps & $\begin{array}{l}\text { Excessive chloramphenicol } \\
\text { residues }\end{array}$ & $\begin{array}{l}\text { No import of fisheries } \\
\text { products in 2 years }\end{array}$ \\
\hline 2002 & Soybeans & $\begin{array}{l}\text { Genetically modified } \\
\text { organism }\end{array}$ & Import restricted \\
\hline 2004 & $\begin{array}{l}\text { Poultry meat } \\
\text { products }\end{array}$ & Bird flu & Import restricted \\
\hline
\end{tabular}

Source: Compiled by Wencong Lu based on Cheng (2002), Ma (2004), Li (2005), Yang (2006) and MOC (2007).

\section{The European Union}

When looking at total exports and imports, the European Union is the largest trading partner for China. However, this is not the case for food exports taken on their own. Despite of the relative small share of food trade in the total amount of bilateral trade, food trade shows an increasing trend over the past few years. In 2006, food exports amounted to US $\$ 4.34$ billion, an increase of 154 percent from 2001. Processed fruits, vegetables and fishery products are the main exports from China to the EU. Although EU import tariffs have been reduced on Chinese food products since its WTO accession in 2001, EU food safety regulations have become more vigorous. With all other things remaining the same, this has exerted a negative influence on exports of Chinese food products to the EU.

In August 1996, the EU closed the import of poultry meat, as well as some fishery and animal products from China because Chinese quality standards for animal products did not meet the producing, breeding, processing and phytosanitary requirements of the EU. For vegetables, fruits and other horticulture products, European requirements demand the levels of pesticide residues to be below certain limits.

Table 4 shows some important cases of food trade friction between China and the EU related to food safety issues. The first restrictions on EU imports on all animal products from China started in 2002. Chinese tea exports to the EU in 2001 were found to have overly high pesticide 
residue levels. These restrictions to the EU have resulted in a trade loss for Chinese food producers and enterprises. The EU import prohibition on Chinese animal products in 2002 alone resulted in a US\$ 623 million loss to 94 Chinese food-processing enterprises (MOC, 2005). In addition, the EU restricted the import of peanuts from China in 2004 and 2005 because of high levels of aflatoxin (Chao 2006). In November 2006, Chinese canned asparagus with white heads were called back and restricted in Denmark and then the EU warned all consumers about this product because of inadequate heating treatment in the processing.

TABLE 4: EU import restrictions on Chinese food products

\begin{tabular}{|c|l|l|l|}
\hline Year & \multicolumn{1}{|c|}{ Product } & \multicolumn{1}{|c|}{ Problems } & \multicolumn{1}{c|}{ Trade impacts } \\
\hline 1997 & $\begin{array}{l}\text { Bivalve fishery } \\
\text { products }\end{array}$ & Excessive antibiotic chloramphenicol & Import restricted \\
\hline 1998 & Hare meat & Uncertified process & Import restricted \\
\hline 1999 & Honey & Excessive chloramphenicol residues & $\begin{array}{l}\text { US\$ } 1.1 \text { billion trade } \\
\text { loss }\end{array}$ \\
\hline 1999 & Peanuts & Excessive aflatoxin residues & Import restricted \\
\hline $2001-02$ & Tea & Excessive pesticide residues & Import restricted \\
\hline 2001 & Shrimps & Excessive antibiotic residues & Import restricted \\
\hline 2001 & Poultry & Excessive antibiotic residues & Import restricted \\
\hline 2002 & Honey & Excessive chloramphenicol residues & Import restricted \\
\hline 2003 & Hare meat & Uncertified process & Import restricted \\
\hline 2003 & Canned oranges & Excessive antibiotic residues & $\begin{array}{l}\text { Import restricted for } 9 \\
\text { month }\end{array}$ \\
\hline 2004 & Peanuts & Excessive aflatoxin residues & Import restricted \\
\hline 2006 & Canned asparagus & Uncertified process & Shipments rejected \\
\hline
\end{tabular}

Source: Compiled by Wencong Lu based on Cheng (2002), Zhang (2003), Peng (2006), Huang (2005), Wang (2006) and RASFF (2006).

\section{Japan}

Japan is traditionally the main export destination of Chinese food and agricultural products. Total exports of Chinese food to Japan amounted to US $\$ 8.2$ billion in 2006, one-third of the total of Chinese food exports. In recent years, Chinese exports of fruits, vegetables and seafood to Japan have been the main targets of restricted imports. Table 5 shows several key cases of the lack of market access faced by China in Japan since 1997. In 2002 and 2003, the export of Chinese frozen spinach to Japan was forbidden because of too high traces of pesticide residues, which led to a decrease of US\$372 million compared to the trade value in 2001.

Japan has in place stringent food safety requirements that have resulted in frequent constraints on imports of processed meat and fishery 
products. In 1999, the import of meat products from China was restricted due to the lack of certification in the production process. In 2004, the import of frozen shrimps from China was restricted as a result of high residue levels of the antibiotic chloramphenicol.

The Japanese government introduced in May 2006 new food safety standards called the 'Positive List System' which included more than 40,000 items involving almost all food products. The new Japanese standards will probably result in an increase in bilateral food trade frictions with China. In the short term, they will hinder Chinese food exports, but in the long run they should contribute to improve Chinese food product quality.

TABLE 5: Japan's import restrictions on Chinese food products

\begin{tabular}{|c|c|c|c|}
\hline Year & Product & Problem & Trade impact \\
\hline 1999 & Meat products & Uncertified process & $\begin{array}{l}\text { Increased production } \\
\text { cost }\end{array}$ \\
\hline 2001 & $\begin{array}{l}\text { Onions and mush- } \\
\text { rooms }\end{array}$ & n.a. & $\begin{array}{l}\text { Import restricted for } 200 \\
\text { days }\end{array}$ \\
\hline 2002-03 & Eel products & $\begin{array}{l}\text { Excessive antibiotic } \\
\text { residues }\end{array}$ & Import restricted \\
\hline 2002 & Frozen chicken & $\begin{array}{l}\text { Excessive antibiotic } \\
\text { residues }\end{array}$ & Import restricted \\
\hline 2002 & Tea & $\begin{array}{l}\text { Excessive pesticide } \\
\text { residues }\end{array}$ & Import restricted \\
\hline 2002-03 & Frozen spinach & $\begin{array}{l}\text { Excessive pesticide } \\
\text { residues }\end{array}$ & Import restricted \\
\hline 2002 & Milled rice & Unqualified package & Import restricted \\
\hline 2004 & Vermicelli & $\begin{array}{l}\text { Excessive benzyl perox- } \\
\text { ide residues }\end{array}$ & Mandatory inspection \\
\hline 2004 & Frozen shrimps & $\begin{array}{l}\text { Excessive chlorampheni- } \\
\text { col residues }\end{array}$ & Import restricted \\
\hline 2006 & Peas & $\begin{array}{l}\text { Excessive pesticide } \\
\text { residue }\end{array}$ & Import rejected \\
\hline
\end{tabular}

Source: Compiled by Wencong Lu based on Cheng (2002), IBN (2004), Wang (2006), MOC (2006), Yang (2006) and China News (2006).

\section{Lower food safety standards in China}

In spite of the significant development China has experienced through the last 20-25 years, especially in the eastern provinces of the country, China is still on average a country with a low GDP per capita compared to the USA, the EU and Japan. There is a close relationship between the level of the food safety regulations in a country and the living standard of the people. In high income countries there is a greater demand for food security, and it is also easier to supply a higher level of food safety. 


\section{Cases of lower food safety standards in China}

There exist obvious differences in food quality standards between China and its main trade partners. As a developing country, China has just started to pay more attention to the quality of food in recent years instead of only being interested in output volume. Most of the current Chinese standards set up years ago cannot meet the requirements of the ISO (International Standards Organization) and CAC (Codex Alimentary Commission) standards accepted widely in nearly all developed countries. For example, more than 90percent of present food standards in Japan are consistent with international standards, as against China's 15 percent. The residue maximum rules in Japan comprise 53,862 standards, concerning the usage of 797 pesticides, veterinary drugs and food additives. 25 percent of these standards are stricter than Chinese national standards involving 61 kinds of main food and processed food exported to Japan. The European standard for pesticide residue in tea established in 2000 requires the content of chloramphenicol at maximum $0.1-0.3 \mu \mathrm{g} / \mathrm{kg}$ which diminishes the level by 100-200 times compared to the previous standard. The EU food safety standard level is also higher than the Japanese standard $(50 \mu \mathrm{g} / \mathrm{kg})$ and the American standard $(4-5 \mu \mathrm{g} / \mathrm{kg})$.

The Chinese standards in general are lower than in the developed countries. In addition, it is important to note, that even those food safety standards are not widely used by many small and medium enterprises (SMEs) in Chinese food and food-processing industry, due to a lack of the necessary public monitoring.

\section{Difficult for the farm and food processing sectors to comply with high standards}

Many of China's food safety problems can be traced back to the production system at farm level. China has one of the world's highest rates of chemical fertilizer and pesticides use per hectare. Antibiotics are widely used to control disease in livestock, poultry, and aquaculture products. Over-use of chemicals, especially fertilizer and pesticides in farming and food additives in the food-processing industry, not only reduce the quality of products, but also pollute agricultural environment.

The pollution problems and food safety problems are either caused by no regulations or too lax regulations on the one side, or to the lack of observing the rules. In the short term, the farmers are interested in few and weak regulations, and when confronted with rules they have an incentive not to follow the rules. The farmers often lack knowledge 
about methods of production if they follow the rules and do not have any knowledge about the alternative possibilities. Even if they do have such knowledge, they may have an incentive to not observe the rules, because the alternative production methods are more costly.

At present, the local use of traditional technology is not sufficient to deal with the problems encountered. In order to increase revenue from food export activities, technological and scientific assessments need to focus on improving food safety and quality. At present, technologies for agricultural production and food-processing in China are dominated by traditional approaches. Chinese food producers face rising production cost when implementing stricter food safety standards. On the supply side, it is difficult for the farming sector and the food processing sector to observe more stringent environmental and food safety regulations.

In addition, it should be emphasized that the introduction of new improved standards has suffered from weak administration also involving corruption at different levels.

\section{Difficult to establish the necessary infrastructure for food safety}

China is still in the process of developing its infrastructure necessary for food safety to be implemented. Laboratories for investigating the content of food items are necessary, food advisory boards informing about food safety and assisting in implementing food safety measures have to be established, and food control systems should be able to monitor that the rules are being observed.

Although China has established 35 national centres, 443 departmental institutions and over 300 laboratories for food quality inspection, its quality management systems are still insufficient to efficiently assist and supervise the production of the increasingly expanding number of the small and medium sized enterprises in the food industry. Chinese food industries should be encouraged to further develop food certification systems, such as ISO-9000/14000 standards and Hazard Analysis and Critical Control Point (HACCP), to ensure food safety and quality.

\section{Chinese Efforts to Improve Food Safety}

To ensure food safety is not an easy task. There is a whole chain of elements which should be fulfilled before food safety is a reality. Firstly, some food safety regulations with reasonable limits or standards have to be set. Some institutions have to be in charge of these decisions and these decisions should be based on scientific evidence and other impor- 
tant concerns. Secondly, when the regulations are set, the information about the regulations should be disseminated to all the producers and distributors involved in food production. Thirdly, some institutions should assist the producers and distributors to implement the rules. The farming methods and the food processing techniques may have to be changed and that might involve new physical investments and investments in human capital. Incentive systems which encourage production to observe the food safety regulations should be introduced. Fourthly, monitoring institutions should ensure that the regulations are all observed by the producers and the distributors. Certification can be a method to ensure that products delivered from certain producers do fulfill the requirements they presented to observe.

To meet the food safety standards of the developed countries (a prerequisite for being successful in those markets), provides China with a powerful incentive and pressure to promote the administrative and technical capacities for food safety management. This needs the development of institutional structures, physical infrastructure, and human capital. China is in the midst of a campaign to overhaul its food system and improve safety standards. Both the Chinese government and the private sector have made great efforts in the past years to this end. Some important policy measures and management strategies are reviewed in the following section.

\section{Changes in the food safety rules}

As a response to increased public awareness and concern about food safety, there have been significant institutional changes in food safety regulations. Now the Chinese government has five ministries in charge of food safety issues namely: the Ministry of Agriculture (MOA); the Ministry of Health (MOH); the General Administration of Quality Supervision, Inspection and Quarantine (AQSIQ); the State Food and Drug Administration (SFDA); and the State Environmental Protection Administration (SEPA). The responsibilities of these ministries are clearly divided as shown in Table 6.

In the recent past there have been important changes of the rules related to hygiene standards, the use of inputs and the certification of firms (see Table 7).

Hygiene standards: A series of important regulations regarding hygiene issues has been established and revised in China recently. For example, in accordance with the Principles for the Establishment and Application of Microbiological Criteria for Food of the Codex Alimentarius Com- 
TABLE 6: Main responsibilities of Chinese ministries for food safety

\begin{tabular}{|c|c|}
\hline Ministries & Responsibilities \\
\hline $\begin{array}{l}\text { Ministry of Agriculture } \\
\text { (MOA) }\end{array}$ & $\begin{array}{l}\text { - } \quad \text { Agricultural production; } \\
\text { - } \quad \text { Animaduction materials for Agriculture; } \\
\text { - } \quad \text { Entry and exit of animal and plant quarantine; } \\
\text { - } \quad \text { Supervising the safety of GMO; } \\
\text { - } \text { food; } \\
\text { - Agricultural extension. }\end{array}$ \\
\hline $\begin{array}{l}\text { Ministry of Health } \\
(\mathrm{MOH})\end{array}$ & $\begin{array}{l}\text { - } \quad \text { Establishing and revising food hygiene standards; } \\
\text { - } \quad \text { Monitoring food sanitation; } \\
\text { - Issuing hygiene license to food producer and traders. }\end{array}$ \\
\hline $\begin{array}{l}\text { General Administration } \\
\text { of Quality Supervision, } \\
\text { Inspection and Quaran- } \\
\text { tine (AQSIQ) }\end{array}$ & $\begin{array}{l}\text { - } \quad \text { Monitoring, inspecting and testing food quality; } \\
\text { - } \quad \text { Certification, accreditation and standardization of } \\
\text { food enterprises. }\end{array}$ \\
\hline $\begin{array}{l}\text { State Food and Drug } \\
\text { Administration (SFDA) }\end{array}$ & $\begin{array}{l}\text { - Safety supervision of food, healthcare products and } \\
\text { cosmetics; } \\
\text { - Investigating and treating key food accidents. }\end{array}$ \\
\hline $\begin{array}{l}\text { State Environmental } \\
\text { Protection Administra- } \\
\text { tion (SEPA) }\end{array}$ & $\begin{array}{l}\text { - } \quad \text { Establishing environmental quality standards } \\
\text { - } \quad \text { Setting up the rules and regulations of environment } \\
\text { - }\end{array}$ \\
\hline
\end{tabular}

Source: authors' own presentation

mission (CAC), administered by the FAO and the $\mathrm{WHO}$, the $\mathrm{MOH}$ has enacted 19 different hygiene rules for processing and transportation of products made of soya, plant oil, honey, milk, meat and other food products since 1988. The Hygienic Registration of Food Exportation regulation, revised by the State Administration of Quality Supervision, Inspection and Quarantine (AQSIQ) in 2002, requires all enterprises manufacturing frozen vegetables, meat, tins, water products, drinks, tea and sugar to register detailed information about the raw material, subsidiary material, processing, packaging, storage and transportation of the products for export, as well as where they are produced.

The use of inputs: Some more advanced technologies to reduce inputs of fertilizers, pesticides and growth hormones in agricultural production are recommended by the MOA in order to ensure food safety and realise agricultural environmental sustainability. The usage of some food additives in the food-processing industry is forbidden by the AQSIQ due to their negative effects on human health. Imports of raw food inputs in the production process are inspected by the AQSIQ. 
TABLE 7: Main Chinese laws and regulations for food safety

\begin{tabular}{|c|l|c|}
\hline Year & \multicolumn{1}{|c|}{ Laws and regulations } & $\begin{array}{c}\text { Administrative } \\
\text { departments }\end{array}$ \\
\hline 1995 & Food Hygiene Law & MOH \\
\hline 1997 & Regulation of Pesticide Management & MOA \\
\hline 1999 & Regulation of Feed and Additives Management & MOA \\
\hline 1999 & Regulation of Hygiene of Food Trade & MOH \\
\hline 2000 & Product Quality Law & AQSIQ \\
\hline 2001 & Regulation of GMO Safety Management & MOH \\
\hline 2001 & Regulation of Food Additives Hygiene & SEPA \\
\hline 2001 & Rule of Organic Food Certification & MOA \\
\hline 2002 & Agriculture Law & MOA \\
\hline 2002 & Regulation of Animal Quarantine & MOA \\
\hline 2002 & Regulation of Pollution-Free Agricultural Products & AQSIQ \\
\hline 2002 & $\begin{array}{l}\text { General Rule of Examination on Market Access of } \\
\text { Food Safety }\end{array}$ & SEPA \\
\hline 2003 & Organic Food Standards & AQSIQ \\
\hline 2003 & $\begin{array}{l}\text { Regulation of Quality Supervision of Food-processing } \\
\text { Industries }\end{array}$ & $\begin{array}{l}\text { MOH } \\
\text { Standard }\end{array}$ \\
\hline 2004 & Regulation of Food Safety Improvement & SFDA \\
\hline 2004
\end{tabular}

Source: authors' own presentation

Market access licences: In 2004, China began to issue domestic market access licenses for food products based on an examination by the AQSIA of production conditions and quality standards in the food and foodprocessing enterprises. Market access licenses were initially applied for meat, milk, spices, edible oils, rice, cookies, noodles and about 60 other agro-food products.

\section{Information systems for food safety}

Since 2003, an information system for food safety in different administrative regions in China has gradually been developed. This system serves to identify the source and cause of food pollutants. The goal is to reduce the residues of pesticide and veterinary pharmaceutical residues, environmental pollutants and other harmful chemical substances, such as nitrosamine in food production and processing. The system also monitors inputs and intermediate products imported from other countries. This system measures the chemical and biological pollutants remaining in primary and processed food items. At present, over 70 information stations are located in 18 Chinese provinces. In addition, a national information centre and 12 provincial laboratories were built between 2004 and 2005 to conform to the environmental and health requirements of the WHO. 


\section{Technical Training for food producers and managers}

It is important for China to avoid an excessive use of chemical inputs in the initial phases of the food production. In order to avoid this, the local governments provide training for farmers and food processing firms on how to use fertilizers, pesticides, veterinary drugs, feed additives and animal and plant hormones with due care and attention. Local governments under the leadership of the MOA are involved in organizing seminars for the producers and managers from food enterprises to help them to understand and acquire environment-friendly production techniques, knowledge and new technologies, as well as information to allow them to adhere to national food quality standards.

\section{Reorganization of food production}

Given the considerable number of small farmers and small and medium sized enterprises in food industries, China started a reorganization of food production in the mid-1990s. Chinese farmers, food-processing enterprises and marketing companies have been encouraged to increase the vertical integration of the food and food-processing industries. The vertically integrated production organization is not only useful in helping to increase economic efficiency, but also as a means of introducing standardized production methods, which improve food product quality. In China the basic form of vertical integration is a co-operation between a food processing firm and a number of farmers delivering the inputs. The processing firm makes a standardised contract with farmers. If the food processing firm has a great number of farmers attached as suppliers, the firm is a called a 'dragon-head enterprise'. These firms are seen as a driving force to increase the value-added of agricultural products, and they are the main player in both the national and international markets. In 2004 there were 600 enterprises at the national level, having production units in several different provinces. A further 2,000 enterprises at the provincial level have production units in different parts of the province. At the county level, there are several thousand 'dragon-head enterprises'. According to statistics compiled by the MOA, the national average number of farmers grouped under a national 'dragon-head enterprise' totalled 1,687 in 1996 and declined to 1,622 in 1998 and 899 in 2000 . Farmers are required to adopt the standardized technologies in food production offered by the 'dragonhead enterprise'. Besides providing high-quality seeds for planting, the 'dragon-head enterprise' mainly delivers advisory services on the rational use of pesticides and fertilizers to the farmers in its group. 
The food products are processed and marketed by the 'dragon-head enterprise' under a uniform package and trade mark.

\section{Certification schemes}

The provincial governments have introduced a certification scheme for the food producers. The certification schemes ensure that the certified enterprises are applying production methods which live up to certain standards of environmental protection, of food quality and food safety. The Chinese enterprises have been eager to obtain certification because it allows them to be competitive on domestic and international markets.

There are a series of different certification schemes such as Good Agricultural Practices (GAP), Good Manufacturing Practices (GMP), Good Harvesting Practices (GHP), Sanitary Standard Operating Procedures (SSOP), Hazard Analysis Critical Control Point (HACCP) and International Standard Organization 9000/14000. These schemes have been of some importance. As an example, since the HACCP system was first introduced in the processing of meat, vegetables, juice, fast food and fisheries products by AQSIQ in 2003, more than 4,600 enterprises in the Chinese food and food-processing industries use the HACCP system. It is estimated that the introduction of the HACCP system in China has increased food exports by 4.76 million tons with a value of US $\$ 6.1$ billion. The intention of the Chinese government was to require all enterprises producing meat, vegetables, juice, fast food and fishery products to obtain HACCP certification by the end of 2006. In addition, to ensure food safety at the origin of the product, the systems of GMP and GHP were extended to all Chinese enterprises producing meat, vegetables, juice, canned food, sugar, edible oil and fishery products in 2005.

\section{Implementation of a 'Green Food' strategy}

In 1991, the MOA began to implement a strategy of 'Green Food' in food production in order to ensure the environmental protection and to improve food safety and consequent market competitiveness of Chinese food products. According to this standard, 'Green Food' is classified in two groups, namely 'Green Food A' and 'Green Food AA'. For the production of 'Green Food A', the use of pesticides, fertilizers and other agricultural chemicals is allowed but restricted. For 'Green Food AA', all chemicals are prohibited to be used in the production process. Therefore, Chinese 'Green Food AA' is equivalent to organic food. The MOA has established comprehensive quality standard and certification 
systems concerning the geographical origin, production technology, product standard, packaging and transportation for 'Green Food'. Since 1991, the production of 'Green Food' has increased by over 25 percent on average per annum. There are over 2,800 'Green Food' enterprises with around 6,500 types of products. The export of 'Green Food' is valued to be approximately US\$ 1.5 billion (Xinhua News 2005).

\section{What should be done in the future?}

As shown in the previous section, China has in the recent past, focused more on improving food quality and implementing higher food safety standards than previously. Internationally, the food safety question has become more important, and food safety standards have become more rigorous. At the same time the large increase in living standards in China, especially in the eastern provinces of the country, has caused greater domestic concern about food quality and safety regulations.

These trends will continue in the future. Although important reforms have been started, it is important for China to continue to focus on food quality improvement and food safety standards. The changes which have already been undertaken, as shown in the previous section, have not been implemented in all provinces to the same degree. In each province, there are also significant differences between different areas when it comes to the question of food safety standards and food quality. In addition it is clear that the present situation could be improved by introducing new reforms, as a supplement to reforms already undertaken.

China has two tasks in the future to deal with concerning the issue of quality and food safety. Firstly, the changes already started should be disseminated more broadly in all provinces and in all locations in each province. Secondly, new reforms should be decided and implemented to supplement the reforms which have been put at work.

In order to improve China's export competitiveness and quality of food products, there are new issues that must be faced. In order to successfully meet the challenges ahead, the following suggestions are outlined.

\section{Reform of the administration system}

Today food safety is regulated by several governmental ministries and entities at the national level. There are the Ministry of Agriculture; the Ministry of Health; the Ministry of Commerce; the State Administration of Quality Supervision, Inspection and Quarantine; the State Food and Drug Administration; and other agencies. Each of these institutions 
contributes to the food safety policies, and they often have overlapping responsibilities.

Different institutions at the national level and at the provincial level are dealing with the same issues. The problems with this arrangement are evident. The lack of clear delimitation of the authority of each institution opens up for conflicts about responsibility. It also opens up for too much administration in some areas and too little administration in other areas. If the borderlines between the activities of the different institutions were clearer, it would be easier to decide a coherent set of rules. It would be easier to both implement the rules and to monitor that they are observed by the firms and local authorities.

\section{Different food safety regulations at different levels}

There are food safety regulations at the national level, at the provincial level and at the local level. In addition at the industry sector level there are associations of firms setting food standards levels for specific products.

Often the food standards decided by the associations of firms are higher than provincial and national food safety standards. The associations count exporting firms among the members, and they are interested in having standards which follow the international safety standards on the export markets.

The standards at the provincial level vary between the rich provinces in the east and the poorer provinces in the west. The national standards are often more lax than the standards in the provinces in the east.

It is clear that these different standards are complicating the situation both for the producers and the consumers. Moreover, it seems unrealistic to implement only one set of rules, because a set of 'average' rules would neither fulfill the demands of the exporting firms nor the different demands in the richer and poorer provinces.

The goal in the long run should be to implement regulations which correspond to international standards. The more they are applied in China, the easier it will be for Chinese enterprises to compete on the world market. In addition, it should be remembered, that 70 percent of food processing enterprises in China are small or medium-sized firms.

However, for the poorer provinces it is important to get as close as possible to the level of the richer provinces, because otherwise the 'export' possibilities to the richer provinces will be hampered.

In fact, some differences in standards may be desirable at present due to of the large differences between the levels of development in the different provinces. It is up to the individual firm in the western provinces 
to decide if it will agree on a quality level acceptable for opening up the possibility of 'export' to the eastern provinces.

In the long run the goal should be one common standard for the whole Chinese market. Administratively, it is evident, that it is more costly for small and medium sized firms to adjust to a series of different rules. The single market in the EU with the same product standards for all countries has proved to reduce costs and to increase internal competition.

\section{Improving the information service systems}

Effective and timely information are vital ingredients for farmers and food processing enterprises to allow them to take proper production decisions and develop reasonable management strategies. Governments have a role to play in assisting farmers and food processing enterprises to catch up with changes in export markets, gain information on international market access requirements and be aware of developments in food production technologies. Based on sufficient information, farmers and food processing enterprises can adjust food production and determine whether to adopt or develop new technologies.

\section{Supporting technical changes}

Technical changes in food production and processing should be regarded as the core elements in improving food quality and export competitiveness in the Chinese food industries. A national net of technical advisory services should be established in order that small and medium sized enterprises in western China, and other less-developed areas, can also take advantage of opportunities to access new technologies in food production and processing.

As already mentioned, most of the food processing firms in China are small or medium-sized firms which do not have the capacity to deal with research and development activities. Therefore, research and development should take place at the sectoral level. It should be the tasks of public authorities to stimulate the interest in R\&D activities at the sectoral level, which could also improve the product quality and the production methods, which are often linked together.

\section{Strengthening vertical cooperation between farmers and enterprises}

While the number of 'dragon-head enterprises' that are integrated with farmers in the food sector has increased markedly in the past few years, these enterprises are mainly located in the eastern coastal regions of China. It is important, and also possible, to improve export 
competitiveness at the national level by developing different kinds of vertically integrated food production organizations in western China, where farmers have less information and knowledge on food production technologies and marketing. At the same time, a regional cooperation mechanism between food enterprises in different parts of China should be developed through transferring capital and technologies from the eastern coastal to the middle and western regions. This would enable full use of regional comparative advantage since natural resource-endowed Chinese middle and western regions lack capital and technologies in food and food-processing industries, while the opposite is true in the developed eastern coastal areas.

\section{International transfer of know-how}

China is focusing on improving food quality and introducing environmental friendly production methods. Fulfilling these goals demand technical changes. China should consider to what extent these goals can be reached in an adequate way by 'buying' know-how internationally.

When foreign investments are taking place improved technology, improved marketing and improved management are relevant parts of the whole package. Foreign investments are of especial interest, if they have an important spillover effect upon the domestic firms in the area.

\section{Conclusions}

When discussing food safety issues, the conflict of interests between developed and developing countries is often brought up. It can be said that the developed countries have higher standards than developing countries, which hamper the export possibilities.

It is an interesting question as to whether high food safety standards are protective or protectionist measures. The Sanitary and Phytosanitary Agreement, which has been decided by the WTO members, sets the rules for what the developed countries are allowed to do, and what the developing countries can do if they believe the food safety standards are disguised as protectionist means. This issue is not dealt with in this article.

The authors assume that the high food safety standards in the developed countries are legitimate. Following this, questions can be raised. What are the consequences of these standards? What has China done to overcome some of the problems? What can China do in the future to improve the situation?

Concerning the first question, the article aimed to show that Chinese exports of its main food export items have had difficulties in fulfilling 
the international standards on the main markets in the USA, the EU and Japan. In a series of cases, Chinese exports have been restricted.

As an answer to the second question, the article suggests that the high international standards have had a dynamic impact on Chinese food economy. China has tried to adjust to the high international standards by focusing on food quality improvements, although it is a long term task to improve the food safety regulations, to implement the regulations and to monitor that they are observed by the producers. The article enumerates several important steps being taking in the recent past.

In spite of progress China, still has to introduce further reforms. As an answer to the third question, the authors put forward a number of important suggestions for the future. Administrative reforms are necessary. The safety standards differ between the national, the provincial and the sectoral levels, but the introduction of one set of rules is not possible at present. In addition, improved information systems are needed, technological changes in the farming sector and food industry should be encouraged, the vertical integration between farmers and the food industry should be enforced, and finally, the extent to which China should rely on foreign know-how should be considered.

Wencong Lu is professor of agricultural economics at the University of Zhejiang (wenclu@zju.edu.cn). Søren Kjeldsen-Kragh is professor of international economics at the University of Copenhagen (skk@life.ku.dk).

\section{ACKNOWLEDGEMENT}

This study has been possible due to a grant from the Danish International Development Agency (DANIDA).

\section{REFERENCES}

AQSIQ (Administration of Quality Supervision, Inspection and Quarantine of China) 2006. Annual Report of Chinese Technical Trade Measures 2006, Beijing.

Calvin, L. and D. Hu 2006. Food Safety Improvements Underway in China. Amber Waves volume 4, Issue 5, Economic Research Service/USDA, Washington, D.C.

China News 2006. Available from: http://news.china.com/zh_cn/finance/11009723 / 20060918 /13633328.html [accessed 1 December 2006]

China Daily, 11 June 2003.

Caswell, J. 2003: 'Trends in Food Safety Standards and Regulation: Implications for Developing Countries'. In L. Unnevehr (eds). Food safety in Food Security and Food Trade. International Food Policy Research Institute, Washington, D.C.

Cheng, G.Q. 2002. 'Exportation of Chinese Agricultural Products Faces Technical Trade Barriers'. High-Technology E Industrialization, No.11. 
Wencong Lu and Søren Kjeldsen-Kragh

European Commission 2006. 'Alert Notifications'. Rapid Alert System for Food and Feed (RASFF). Week 2006/45, No. 2006.0794.

GAC (General Administration of Customs of China). Chinese Statistical Custom Yearbook, various years.

Hong, L. 2006. 'The Comment on the Impacts of Technical Trade Barriers on China's WTO Entry and Her Commitment'. World Trade Organization Focus, No.6.

Huang Y.J. 2005. 'EU's Banning of Honey Import from China: Response Strategy and Inspiration'. Journal of International Trade, No.2.

Jaffee, S.M. and S. Henson 2005: 'Agro-Food Exports from Developing-Countries: the Challenges and Posed by Standards'. In Aksoy, M. A. and J. C. Beghin (eds). Global Agricultural Trade and Developing Countries. The World Bank, Washington, D.C.

Li, H.D. 2005. 'Analysis of the Reason and Countermeasure of the Chinese Agricultural Products Blocked by the Green Barriers'. Journal of Harbin Commerce University, No. 5.

Ma, W.J. 2004. 'Technical Trade Barriers of Farm Produce in America'. World Agriculture, No.11.

MOC (Chinese Ministry of Commerce) 2006. Available from: http:/ / sms.mofcom.gov. cn/aarticle / wangzhanjianjie/feihuiyuan/200607/20060702628563.html [accessed 15 September 2006]

MOC (Chinese Ministry of Commerce) 2007. Agricultural trade Issues and Countermeasures. Available from: http:/ / www.mofcom.gov.cn/aarticle/o/ dg/200701/20070104284566.html [accessed 15 April 2007]

NBSC (National Bureau of Statistics of China). Chinese Food Industries Yearbook, various years.

OECD 2004. Addressing Market-Access Concerns of Developing Countries Arising from Environmental and Health Requirements: Lessons from National Experiences. OECD Trade Policy Working Paper No.5.

Peng, C. 2006. 'The Effect of Technical Trading Barrier and its Countermeasures: A Case of Peanuts Export'. Theory Journal, No.11.

Roberts, D., T. Josling, and D. Orden 1999. A Framework for Analyzing Technical Trade Barriers in Agricultural Markets. Market and Trade Economics Division, Economic Research Service, U.S. Department of Agriculture. Technical Bulletin No. 1876, Washington, D.C.

Wang, Z.Y. 2006. 'Chinese and Japanese agricultural product trade friction question research'. Market Modernization, No.19.

World Bank 2005: Food Safety and Agricultural Health Standards: Challenges and Opportunities for Developing Country Exports. Report No. 31207.

International Business Newspaper (IBN), 12 October 2004.

Wu, L. 2004. 'The Eel Crisis Expedites New Mechanism for Food Safety Control'.

Yang, Z.J. 2006. 'Nontariff Barrier: Challenge to Chinese Aquatic Product Export'. Journal of Wuhan Scientific and Technical University, No.1.

Xinhua News 2005. Rapid Development of Organic Food Industry in China. Available from: http://news.xinhuanet.com/newscenter/2005-06/07/content_3055172.htm [accessed 15 May 2007]

Zhang, Y.A. 2003. 'The Impact on Export of Chinese Agricultural Products from US Green Barrier'. World Economic Research, No.1. 